3 Wells, S. A., jun., et al., Fournal of Thoracic and Cardiovascular Surgery, $1973,66,557$.

4 Ioachim, H. L., Dorsett, B., and Paluch, E., presenied at the X1th International Cancer Congress, Florence, October, 1974

${ }^{5}$ Krant, M. J., et al., Cancer, 1968, 21, 623.

6 Ducos, J., et al., Lancet, 1970, 1, 1111.

${ }^{7}$ Han, T., and Takita, H., Cancer, 1972, 30, 616.

8 Anthony, H. M., et al., Clinical Experimental Immunology 1974, 20, 29

Anthony, H. M., personal communication, 1975.

10 Israel, L., Mugica, J, and Chahinian, P., Biomedicine, 1973, 19, 68.

11 Gross, R. L., et al., New England fournal of Medicine, 1975, $292,439$.

12 Wells, S. A., jun., National Cancer Institute Monographs, 1973, 37, 197.

13 Renoux, G., and Renoux, M., Comptes Rendus Hebdomadaires des Séances de l'Académie des Sciences Paris, 1971, 272, 349.

14 Symoens, J., and Brugmans, J., Fogarty International Center Proceedings, No. 28, Washington, D.C., U.S. Government Printing Office, in press. ${ }^{15}$ Lancet, 1975, 1, 151.

${ }^{16}$ Chirigos, M. A., Pearson, J. W., and Pryor, J., Cancer Research, 1973, 33, 2615.

${ }^{17}$ Mantovani, A., and Spreafico, F., Bolletino dell'Istituto Sieroterapico Milanese, 1974, 53, 302
18 Tripodi, D., Parks, L. C., and Brugmans, J., New England fournal of Medicine, 1973, 289, 354.

19 Hirshaut, Y., et al., Proceedings of the American Association for Cancer Research, 1973, 14, 109.

20 Verhaegen, H., et al., New England fournal of Medicine, 1973, 289, 1148.

21 Biniaminov, M., and Ramot, B., Lancet, 1975, 1, 464.

22 Verhaegen, H., et al., Lancet, 1975, 1, 978.

23 Slack, N. H., Cancer, 1970, 25, 987.

${ }^{24}$ Amery, W., Lancet, 1975, 1, 574.

${ }^{25}$ Cole, W. H., Surgery, Gynecology and Obstetrics, 1973, 137, 853.

${ }^{26}$ Lancet, 1974, 2, 817.

${ }^{27}$ Han, T., Lancet, 1972a, 1, 742.

28 Han, T., Clinical Research, 1972b, 20, 566.

29 Kwan Park, S., et al., Lancet, 1971, 1, 53.

${ }^{30}$ Cochran, A. J., et al., British Medical fournal, 1972, 4, 67.

${ }^{31}$ Cochran, A. J., et al., Yale Fournal of Biological Medicine, 1973, 46, 650.

32 Vose, B. M., and Moudgil, G. C., British Medical fournal, 1975, 1, 56.

${ }^{33}$ Vaage, J., Cancer Research, 1973, 33, 493.

34 Belehradek, J., et al, in Proceedings of the XIth International Cancer Congress, ed. P. Bucalossi, U. Veronesi, and N. Cascinelli, Vol. 5, p.35, Amsterdam, Excerpta Medica, 1974.

\title{
Carrier Solutions for Low-level Intravenous Insulin Infusion
}

\author{
E. W. KRAEGEN， L. LAZARUS， HELEN MELER， LESLEY CAMPBELL， Y. O. CHIA
}

British Medical fournal, 1975, 3, 464-466

\begin{abstract}
Summary
In the use of low-level intravenous insulin infusion for treating diabetic hyperglycaemia and ketoacidosis adsorption of insulin to containers or plastic infusion apparatus results in significant losses of $60-80 \%$ of insulin in dilute physiological saline solution (40 $\mathrm{U} / 1)$. It is therefore necessary to add protein to the carrier solution to minimize losses and maintain a constant delivery rate. Recovery studies showed that $3.5 \% \mathrm{w} / \mathrm{v}$ polygeline solution (polymer of degraded gelatin) was a suitable medium for this purpose, offering some advantages over human serum albumin. A minimum concentration of $0.5 \%$ polygeline was required to ensure adequate delivery of insulin to the patient.
\end{abstract}

\section{Introduction}

Recent reports have shown the effectiveness of low-dose intravenous insulin infusion in the treatment of diabetic hyperglycaemia and ketoacidosis. ${ }^{1-3}$ The observations that insulin is adsorbed to glass and plastic surfaces, ${ }^{4-6}$ however, emphasize that caution is necessary to ensure that sufficient insulin reaches the patient to be effective. It has been reported that $55 \%$ of added insulin is adsorbed by glass and polyvinylchloride containers within 15 seconds of addition of insulin to

Garvan Institute of Medical Research, St. Vincent's Hospital, Sydney 2010, Australia

E. W. KRAEGEN, B.SC., PH.D., Senior Research Officer

L. LAZARUS, F.R.A.C.P., F.A.A.C.B., Director

HELEN MELER, B.sC., Research Assistant

LESLEY CAMPBELL, M.R.C.P., M.R.A.C.P., Research Fellow

Y. O. CHIA, B.SC., Research Student
Ringers' lactate solution, ${ }^{6}$ and that a typical intravenous infusion set adsorbs another $50 \%$ of the remaining insulin.

Reports have shown that addition of human serum albumin (H.S.A.) to dilute solutions containing insulin greatly reduces insulin adsorption. ${ }^{5-7}$ We have used gelatin solutions to mimic the action of serum in insulin radioimmunoassay, ${ }^{8}$ and in later assays substitution of a commercial $3.5 \%$ polygeline solution (polymer of degraded gelatin; Haemaccel, HoechstBehringwerke) proved equally effective. It seemed likely that this medium, which is normally used as a plasma substitute, would also be suitable as an insulin carrier solution. ${ }^{2}$

We describe here studies of the effectiveness of polygeline as a carrier solution for low-level insulin infusion for periods of up to eight hours.

\section{Methods}

We added 20 units of crystalline porcine insulin (Novo Actrapid, concentration $40 \mathrm{kU} / \mathrm{l})$ to the following standard $500-\mathrm{ml}$ containers: (a) a plastic container holding polygeline $3.5 \%$; (b) a glass container holding polygeline $3.5 \%$; (c) a glass container holding saline $0.9 \%$ and H.S.A. $2 \%$ (Commonwealth Serum Laboratories, Melbourne); (d) a glass container holding saline $0.9 \%$; and $(e)$ a plastic container holding saline $0.9 \%$.

The solutions were mixed by agitating the containers, and 15 minutes after the addition of insulin aliquots were taken for assay. The containers were then connected to controlled paediatric drip sets and each adjusted to a flow rate of about $1 \mathrm{ml} / \mathrm{min}$. The effluent was collected.for insulin assay after two and a half, five, and eight hours. The experiment was performed at $22^{\circ} \mathrm{C}$. Immediately after collection samples were frozen in plastic tubes and stored at $-20^{\circ} \mathrm{C}$. Later they were thawed, diluted to $1 / 700$, and assayed for immunoreactive insulin using a commercial radioimmunoassay kit (Sorin, Italy). The quoted content of the original insulin phial was also checked by radioimmunoassay. In pilot studies insulin standard curves set up in buffer and in the above carrier solutions diluted to $1 / 700$ were equivalent.

In a further experiment to investigate the relation of insulin recovery to concentration of polygeline in the carrier solution $500-\mathrm{ml}$ glass infusion containers were set up with saline as a diluent to produce a range of concentrations of polygeline from 0 to $3.5 \%$. After addition of insulin as in the first experiment the solutions were left standing at $22^{\circ} \mathrm{C}$ 
with frequent gentle agitation, and aliquots were taken for insulin assay after 15 minutes and two hours.

Insulin recoveries were expressed as a ratio of the measured to expected insulin concentration. Statistical comparisons were performed by a Wilcoxon test.

\section{Results}

Recovery of insulin from the five combinations of solutions and containers tested are shown in fig. 1. Each point is the mean of duplicate determinations. The overall within-assay precision in determination of insulin recovery was estimated to be $4.7 \%$ from Snedecor's approximation of duplicate differences. 'There was no discernible downward trend in insulin recovery over the eight-hour period in any case. For statistical comparison a mean recovery of insulin ( \pm S.D.) over the time studied was calculated for each case. Mean recoveries were: ( \pm S.D.; $\mathrm{n}=8$ ): $(a)$ polygeline $3.5 \%$ in plastic container $99 \pm 8 \% ;(b)$ polygeline $3.5 \%$ in glass container $88 \pm 11 \% ;(c)$ saline and H.S.A. in glass container $68 \pm 14 \% ;(d)$ saline in glass container $31 \pm 9 \%$; and $(e)$ saline in plastic container $22 \pm 8 \%$. Solutions $a$ to $c$ all gave significantly higher mean recoveries than the two saline control solutions $d$ and $e(\mathbf{P}<0.01)$. There was no

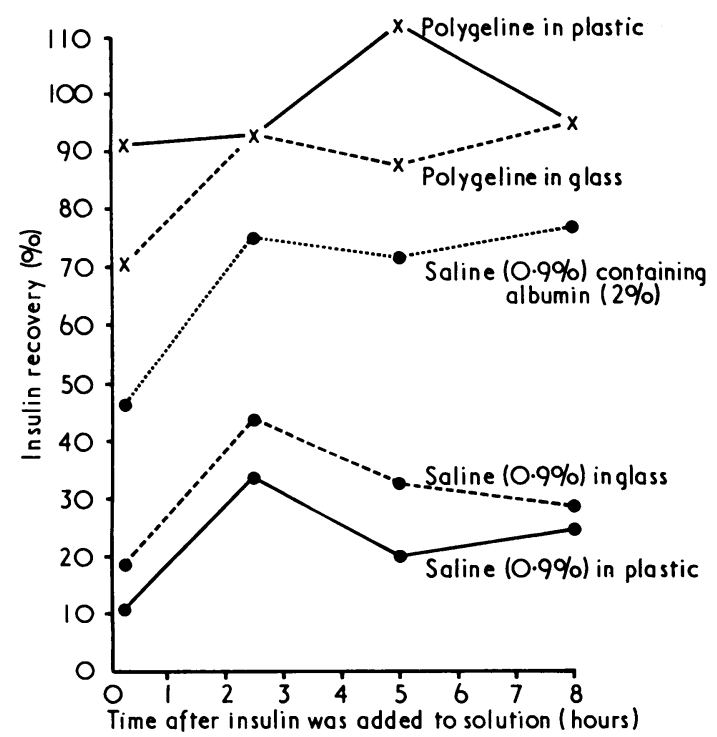

FIG. 1-Recovery of insulin from five carrier solutions in infusion containers as indicated.

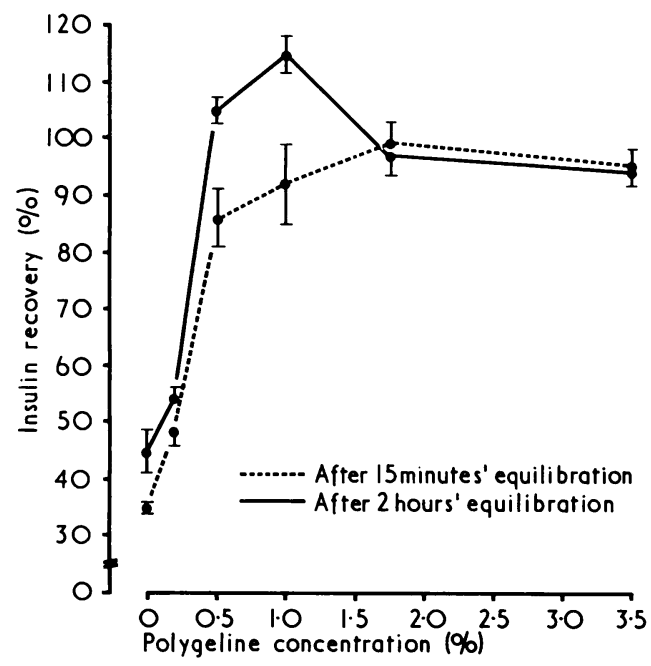

FG. 2-Effect of concentration of polygeline on recovery of insulin. Results are means \pm S.E. of mean. significant effect on mean recovery attributable to container type as assessed by the difference between solutions $a$ and $b$ or between solutions $d$ and $e(\mathrm{P}>0.05)$.

The results of the study to determine the effect of concentration of polygeline on insulin recovery are shown in fig. 2 . Each point is the mean of four determinations. There was a steep increase in insulin recovery up to a concentration of $0.5 \%$ polygeline in solutions tested, with no significant further increase in insulin recovery up to a polygeline concentration of $3.5 \%$. There was no significant difference between insulin recoveries measured after equilibration times of 15 minutes and two hours.

\section{Discussion}

Our results confirm that there are considerable losses of insulin from dilute solutions in contact with normally-used infusion apparatus and that the addition of H.S.A. can greatly reduce this loss. ${ }^{5-710}$ The period of study was extended to eight hours, which is the time considered desirable for delivery of intravenous insulin for control of diabetic ketoacidosis and hyperglycaemia. ${ }^{2}$

A $3.5 \%$ polygeline solution is a suitable substitute for H.S.A. Polygeline solution has three major advantages over a saline and H.S.A. solution. Firstly, it is simple to use, requiring only insulin addition just before use; secondly, it is more readily available than H.S.A.; and, thirdly, it eliminates the slight risk of transmission of infection associated with human blood products.

The recovery of insulin from dilute solution is likely to be influenced by both the surface area in contact with the infusion solution and the concentration of insulin in the carrier solution. ${ }^{6}$ These methodological differences make it somewhat difficult to compare our results with those of others. Nevertheless, our results for recovery from saline and saline plus H.S.A. solutions generally agree with the only other report $^{6}$ which assessed insulin recovery by radioimmunoassay, though the initial recovery of insulin in our studies from saline plus H.S.A. was lower. Recovery assessed by radioimmunoassay is lower than that assessed by recovery of radioactivity after the addition of ${ }^{125} \mathrm{I}$-insulin to the infusion bottle. ${ }^{6}$ This may perhaps be due to non-specific binding of insulin to macromolecules in the carrier solution. It has been shown ${ }^{8}$ that concentrated gelatin solution $(1-4 \%)$ increases non-specific binding of labelled insulin.

From our results we conclude that loss of insulin from dilute solutions in contact with standard infusion apparatus can be substantially reduced (to less than $20 \%$ ) using a commercial $3.5 \%$ polygeline solution, that insulin losses from this solution are no greater than losses from H.S.A. and saline solutions, and that loss of activity of insulin in this medium at room temperature does not increase with time within eight hours. Furthermore, the polygeline solution seems to be equally effective down to concentrations of $0.5 \%$.

Methods of treatment of diabetic ketoacidosis by low-dose constant intravenous insulin infusion vary in the degree of dilution of insulin in the infusion solution. ${ }^{1-3}$ Our studies simulated conditions of insulin delivery in which insulin is diluted to a concentration of $40 \mathrm{U} / 1 .{ }^{2}$ When insulin is present in relatively high concentrations in an infusion syringe $(1-4 \mathrm{kU} / \mathrm{l})$ the fractional insulin loss should be less of a problem. ${ }^{1}$ While we have not studied insulin loss quantitatively in this configuration some precautions against insulin loss may still be desirable if the insulin infusion solution is diluted by parallel connexion with other infusion solutions before intravenous delivery.

The addition of polygeline is now used by us as the standard method of preventing insulin loss during the treatment of diabetic ketoacidosis and hyperglycaemia by low-level constant intravenous infusion. ${ }^{2}$

This work was supported by a grant from the National Health and Medical Research Council of Australia. Requests for reprints should be sent to E. W. Kraegen. 


\section{References}

1 Page, M. M., et al., British Medical fournal, 1974, 27, 687.

2 Kidson, W., et al., British Medical fournal, 1974, 2, 691.

${ }^{3}$ Semple, P. F., White, C., and Manderson, W., British Medical fournal 1974, 2, 694.

4 Hill, J. B., Endocrinology, 1959, 65, 515.

5 Weisenfeld, D., et al., Diabetes, 1968, 17, 766.
6 Petty, C., and Cunningham, N. L., Anesthesiology, 1974, 40, 400.

${ }^{7}$ Wiseman, R., jun., and Balz, B. E., Endocrinology, 1961, 68, 354.

8 Young, J. D., and Kraegen, E. W., Australian fournal of Experimental Biology and Medical Science, 1968, 46, 697.

${ }^{9}$ Snedecor, G. W., Biometrics, 1952, 8, 85.

${ }^{10}$ Frienkel, N., and Goodner, C. J., Fournal of Clinical Investigation, 1960, $39,116$.

\section{SHORT REPORTS}

\section{Deanol in Tardive Dyskinesia}

Tardive dyskinesia is a common and sometimes disabling complication of prolonged treatment with neuroleptic drugs, particularly the phenothiazines and butyrophenones (members of this group include haloperidol and triperidol). ${ }^{1}$ It has caused much concern recently mainly because of its persistent nature, but despite much effort to combat this condition no proper treatment is available. ${ }^{2}$ Though its exact pathophysiology is not clear, the most widely held view is that tardive dyskinesia is due to a hypersensitivity of striatal receptors to dopamine caused by the blocking action on these receptors of phenothiazines and butyrophenones. If this were so one would expect that a drug which would increase the acetylcholine content in the striatum would be effective in controlling tardive dyskinesia, as acetylcholine has antagonistic effects to dopamine at that site. Deanol ${ }^{3}$ has just such properties and has been shown to be effective in the treatment of tardive dyskinesia. ${ }^{4} 5$ It has been used for many years, mainly for the learning and behaviour problems of children and has proved to be remarkably safe. We treated four patients with tardive dyskinesia with deanol not only to confirm earlier reports ${ }^{4}$ but also to determine whether the drug was as effective when given while the offending drug was still being used.

\section{Case Reports}

Case 1. - This 46-year-old woman had been treated for schizophrenia for several years with high doses of thioridazine together with benztropine. She had had a predominantly buccolingual masticatory dyskinesia for some years, which had become severe and disabling for several weeks despite the withdrawal of benztropine. Deanol was started and gradually increased over two weeks to $800 \mathrm{mg} /$ day in divided doses. After one week at this dose the dyskinesia completely disappeared.

Case 2.-This was a 62-year-old woman with presenile dementia, most probably due to Alzheimer's disease, who had received trifluoperazine, followed by thioridazine, in moderate doses for about 10 years. She had concurrently received benztropine till about a year before and had received promethazine some years previously. For a few years she had had buccolingualmasticatory dyskinesia. Deanol was started and gradually increased over one week to $800 \mathrm{mg} /$ day. It completely abolished the dyskinesia on reaching that dose.

Case 3.-This 21-year-old man with mental retardation had been treated with thioridazine in moderate dosage together with benztropine for several years. A few years after starting treatment he had developed a predominantly truncal dyskinesia. Deanol was started and gradually increased to $900 \mathrm{mg}$ day over two weeks, and on reaching this dose the dyskinesia completely disappeared.

Case 4.-This 74-year-old woman with manic-depressive psychosis had been treated with thioridazine in moderate doses for over 10 years. She had also received benzhexol for varying periods. For several years she had had a tardive dyskinesia, consisting mainly of choreiform movements of the limbs and a truncal dyskinesia, but also with grimacing and a slight buccolingualmasticatory dyskinesia. For about 18 months she had been on thiopropazate for her dyskinesia with no appreciable benefit. Deanol $600 \mathrm{mg} /$ day was added and the dose increased up to $1 \mathrm{~g} /$ day over four days. It completely abolished the dyskinesia within six days.

\section{Comment}

For many patients phenothiazine and butyrophenone drugs are essential for the control of their psychiatric state, and it would be a misfortune if these drugs had to be discontinued because of tardive dyskinesia. All our patients received complete relief with deanol while remaining on the offending psychotropic drugs in their usual doses. None experienced side effects, nor was there any evidence of interference with the beneficial effects of the psychotropic drugs, except in Case 2 , in which the tendency this patient had to wander round may have been aggravated, though this was doubtful. Encouraged by these results we have embarked on a double-blind placebocontrolled study of deanol in tardive dyskinesia.

${ }^{1}$ Crane, G. E., American fournal of Psychiatry, 1968, 124, Suppl., 40.

2 Kazamatsuri, H., Chien, C., and Cole, J. O., Archives of General Psychiatry, 1972, 27, 491 .

3 Pfeiffer, C. C., Modern Hospital, 1958, 9, 76.

${ }^{4}$ Miller, E. M., New England fournal of Medicine, 1974, 291, 796.

${ }^{5}$ Casey, D. E., and Denney, D., New England fournal of Medicine, 1974, 291, 797.

Lidcombe Hospital, Joseph Street Lidcombe, New South Wales 2141, Australia

L. DE SILVA, M.R.C.P., Sessional Consultant Neurologist

C. Y. HUANG, M.R.A.C.P., Staff Neurologist

\section{A Dampness Detector for Use with Incontinent Patients}

Incontinent patients often wet the bed at a particular time, especially at night. If such patients are wakened and offered a bedpan or a commode just before that time they may remain dry throughout the night. Once continence is regained in this way it often persists. ${ }^{1}$ We have designed a dampness detector which stops a battery-operated clock immediately a sensing pad placed below the patient becomes wet. The moment when incontinence occurs is thus accurately recorded.

The unit can be constructed with materials costing less than $£ 10$, by a laboratory technician in a few hours. It has proved valuable in the treatment of incontinent patients over the past five years. ${ }^{2}$

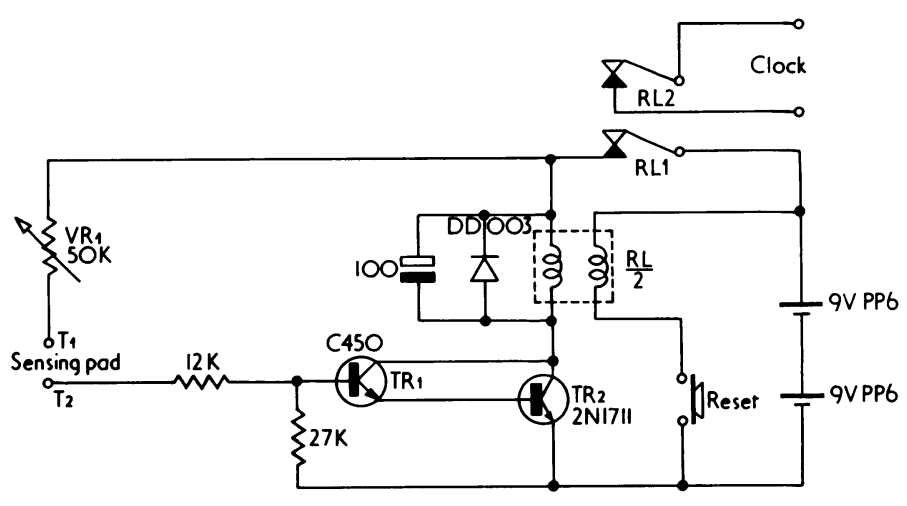

Electrical circuit of dampness detector. 